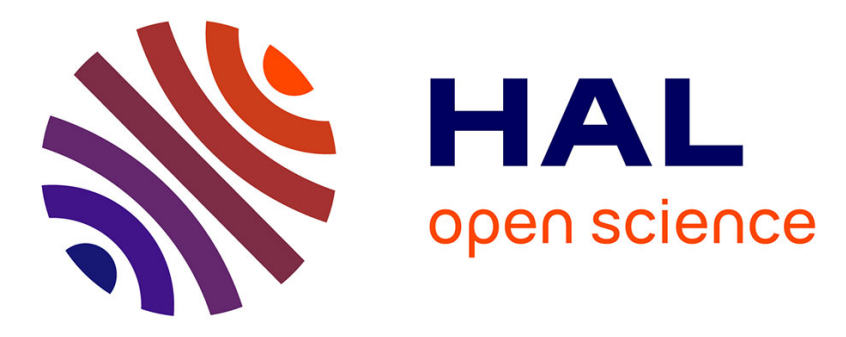

\title{
Immigrant males' knowledge influences baboon troop movements to reduce home range overlap and mating competition
}

Julien Collet, Nathalie Pettorelli, Alice Baniel, Alecia J Carter, Elise Huchard, Andrew J King, Alexander E G Lee, Harry H Marshall, Guy Cowlishaw

\section{To cite this version:}

Julien Collet, Nathalie Pettorelli, Alice Baniel, Alecia J Carter, Elise Huchard, et al.. Immigrant males' knowledge influences baboon troop movements to reduce home range overlap and mating competition. Behavioral Ecology, In press. hal-03463550

\section{HAL Id: hal-03463550 \\ https://hal.umontpellier.fr/hal-03463550}

Submitted on 2 Dec 2021

HAL is a multi-disciplinary open access archive for the deposit and dissemination of scientific research documents, whether they are published or not. The documents may come from teaching and research institutions in France or abroad, or from public or private research centers.
L'archive ouverte pluridisciplinaire HAL, est destinée au dépôt et à la diffusion de documents scientifiques de niveau recherche, publiés ou non, émanant des établissements d'enseignement et de recherche français ou étrangers, des laboratoires publics ou privés. 
1 Immigrant males' knowledge influences baboon troop movements to

2 reduce home range overlap and mating competition

3

4 Julien Collet ${ }^{1, *}$, Nathalie Pettorelli ${ }^{2}$, Alice Baniel ${ }^{3}$, Alecia J. Carter ${ }^{4}$, Elise Huchard ${ }^{5}$,

5 Andrew J. King ${ }^{6,7}$, Alexander E.G. Lee ${ }^{2}$, Harry H. Marshall ${ }^{8}$, Guy Cowlishaw ${ }^{2}$

6

71 Zoology Department, University of Oxford, OX1 3QT Oxford, UK

82 Institute of Zoology, Zoological Society of London, Regent's Park, London NW1 4RY, UK

93 Department of Anthropology, Stony Brook University, Stony Brook, NY, USA

104 Department of Anthropology, University College London, UK

115 ISEM, Université de Montpellier, CNRS, IRD, EPHE, Montpellier, France

126 Department of Biosciences, College of Science, Swansea University, Singleton Park,

13 Swansea, SA2 8PP, UK

147 Institute for Communities and Wildlife in Africa, Department of Biological Sciences, University of

15 Cape Town, Cape Town, South Africa

168 Centre for Research in Ecology, Evolution and Behaviour, University of Roehampton, London, SW15

17 4JD, UK

18 *Author for correspondence, pro@colletj.fr 


\section{Abstract}

Mechanistic models suggest that individuals' memories could shape home range patterns and dynamics, and how neighbours share space. In social species, such dynamics of home range overlap may be affected by the pre-dispersal memories of immigrants. We tested this "immigrant knowledge hypothesis" in a wild population of chacma baboons (Papio ursinus). We predicted that overlap dynamics with a given neighbouring troop's home range should reflect males' adaptive interests in overlap when the alpha male had immigrated from this neighbouring troop but less so when the alpha male originated from elsewhere. We used data collected between 2005 and 2013 on two neighbouring troops in Namibia, comprising GPS records of daily ranges, male natal origins, daily females' reproductive status, and a satellite index of vegetation growth. We found support for our prediction in line with male reproductive strategies but not in line with foraging conditions. In periods with a higher relative number of fertile females over adult males in the focal troop, male baboons would benefit from reducing overlap with their neighbours to mitigate the costs of between-troop mating competition. This was indeed observed but only when the alpha male of the focal troop was an immigrant from that neighbouring troop, and not with alpha males of other origins, presumably due to their different knowledge of the neighbouring troop. Our findings highlight the role of reproductive competition in the range dynamics of social groups, and suggest that spatial segregation between groups could increase through the combination of dispersal and memory.

\section{Keywords}

Home range overlap - Dispersal - Collective decision-making - Spatial memory - Mating competition strategies - Chacma baboons 


\section{Introduction}

How animals use space deeply affects ecological processes (Burt, 1943; Clutton-Brock, 1989; RiotteLambert et al., 2017). Home ranging patterns, when individuals or social units range within restricted areas across their daily lives, are ubiquitous (Börger et al., 2008; Burt, 1943). The size and overlap of adjacent home ranges is variable, and can change through time (Duncan et al., 2015; Kranstauber et al., 2019; Pearce et al., 2013). Classical ecological theory posits that these home range properties are largely determined by the interplay between resource distribution and abundance in the landscape (Duncan et al., 2015; Kelt \& Van Vuren, 2001), and/or the nature of interactions between neighbours: potential mates might be attractive, but rivals and territorially-enforced borders can be repulsive (Börger et al., 2008; Burt, 1943; Clutton-Brock, 1989; Markham et al., 2013). Recent mechanistic movement models suggest that memories acquired by individuals during their life could also be key to understand home range properties (Börger et al., 2008; Riotte-Lambert et al., 2015; Wakefield et al., 2013). According to this latter view, changes in the information possessed by animals ("knowledge"), for instance through learning, could alter subsequent home range shapes and dynamics as well as their consequences on ecological processes (Riotte-Lambert et al., 2017; Spencer, 2012).

In group-living species, the information possessed by social units may also change through demographic processes. While groups may lose information through the loss of keystone individuals due to death or emigration (Brent et al., 2015; Foley et al., 2008), immigrants may bring new and potentially non-local information into the group (Cote \& Clobert, 2007; Jacob et al., 2015; Whiten et al., 2007). In the case of home ranges, the effective transfer of spatial information between groups through individual dispersal, i.e., whether the information carried by an immigrant is shared with its new group, may be dependent on the influence of immigrants on the collective decision-making processes involved in group movements (Couzin et al., 2005), (van de Waal et al., 2013). Nevertheless, where the necessary conditions are met, the exchange of group members between neighbouring social groups could affect how these groups subsequently share space, amplifying or 
buffering the effects of more classical determinants of overlap such as territoriality (Burt, 1943) or competition for resources (Duncan et al., 2015; Kelt \& Van Vuren, 2001). Thus, the origin of immigrants in a troop (as a proxy for their expected knowledge of neighbouring troop's ranges) may help to predict the range overlap dynamics of this troop with the home ranges of its neighbours: the "immigrant knowledge hypothesis".

The immigrant knowledge hypothesis generates several alternative predictions. First, immigrants using their knowledge to visit resources located in the area "traditionally" used by their old (pre-dispersal) group could influence their new (post-dispersal) group to overlap more with their old group than other neighbouring groups. We would then observe higher overlap of a focal troop with a neighbouring home range when immigrants in the focal troop originate from this neighbouring group than from elsewhere, an effect akin to the homogeneizing effect of dispersal classically described in population genetics or cultural transmission theories (Cavalli-Sforza \& Feldman, 1981; Henrich \& Boyd, 1998; Mesoudi, 2018). Alternatively if immigrants do not use memory acquired predispersal and/or if immigrants are not influential on collective decisions (Luncz \& Boesch, 2014; van de Waal et al., 2013; Whiten et al., 2007), dispersal should have no effect on the ranging behaviour of the new host group, and home range dynamics should be poorly predicted by the origin of immigrants. As yet another possibility, immigrants could use their spatial memory to avoid rather than return to the ranging areas traditionally used by their pre-dispersal group (Ellison et al., 2020; Wolf et al., 2009), which could help them to reduce between-group competition (Ellison et al., 2020; Markham et al., 2013; Riotte-Lambert et al., 2017) and/or avoid inbreeding (Alberts \& Altmann, 1995). Overall, immigrant pre-dispersal memory may be expected to have various effects on ranging overlap between neighbours. To our knowledge, however, these ideas have never been tested.

In this study, we investigated the links between immigrant knowledge and home range overlap in chacma baboons (Papio ursinus), by testing whether the origin (and hence expected knowledge) of dominant (alpha) males could help to predict patterns of home range overlap 
between neighbouring troops. Baboons (Papio spp) are well-suited to explore these questions. Baboon troops are not territorial (they do not actively defend or patrol borders) and their home ranges partly overlap with those of their neighbours (e.g. Markham et al., 2013). In this taxon, females are philopatric while males typically disperse to surrounding troops when they reach maturity (Alberts \& Altmann, 1995; Packer, 1979). Male baboons in captivity show long-term memory spanning years (Fagot \& Cook, 2006), suggesting that immigrant males may be able to remember the spatiotemporal distribution of food and other resources used by their pre-dispersal troop. Finally, the collective decision-making processes in baboon groups have been intensively studied (e.g. see review in Montanari, 2019), which helped guide our analyses and interpretations.

In baboon troops, dominant males, and especially alpha males, can have a disproportionate influence on the collective movement decisions (e.g. in three distinct populations of chacma baboons: Kaplan et al., 2011; King et al., 2008; Stueckle \& Zinner, 2008). Such males are likely to have a detectable impact on large-scale troop ranging patterns. Our initial focus was therefore to test the prediction that a focal troop's pattern of overlap with a neighbouring troop would depend on whether or not the focal troop's alpha male was an immigrant originating from that particular neighbouring troop. However, dominant males are not the only individuals that influence collective movement decisions in baboons (Strandburg-Peshkin et al., 2015; Stueckle \& Zinner, 2008), and their influence may be limited to specific contexts and too ephemeral to affect large-scale ranging patterns. We thus also considered whether the observed overlap fitted with the expected adaptive interests of alpha males versus those of other troop members (Conradt et al., 2009; King et al., 2008; Strandburg-Peshkin et al., 2018). In order to do this, we reviewed and synthesized for different group members (males of different origins and dominance rank; females at different stages of their reproductive cycle) their likely preferences for home range overlap with neighbours according to their adaptive interests (food resources, mating strategies). To keep the main text relatively simple and concise, this review is presented in the supplementary information (Appendix S1, synthesized in Tables S1 and S2). In the main paper, we go on to consider the two main predictions for alpha males 
arising from this review, while in the supplementary information we also consider alternative explanations (as well as alternative analytical approaches), such as the potential role of inbreeding avoidance by alpha males (see Appendices S1-S4).

The two predictions we test for the immigrant knowledge hypothesis relate to variation in foraging conditions and mating competition respectively, two key determinants of fitness known to affect range overlap in baboons (Markham et al., 2013). First (Prediction 1), during periods when food is scarce, a focal troop will show greater range overlap with a neighbouring troop's home range when the focal troop contains a knowledgeable alpha male (i.e. an immigrant from this neighbouring troop) compared to when the focal troop has an alpha male that is not knowledgeable (i.e. a natal alpha male, or an immigrant from another troop). This pattern is predicted on the basis that the alpha male will respond to poor foraging conditions by returning to areas where he remembers finding food previously. Second (Prediction 2), when the focal troop contains a relatively higher number of fertile females per adult males (i.e. has a female-biased operational sex ratio), the focal troop will overlap less with the neighbouring troop's home range when the focal troop has a knowledgeable alpha male than when it does not. This pattern is predicted on the basis that males use inter-troop encounters to assess reproductive opportunities, and when a female-biased operational sex ratio in the focal troop increases the likelihood of male immigration from the neighbouring troop (with its associated challenges for the alpha male position and infanticidal attacks on the alpha male's offspring), the alpha male will avoid those areas where he knows encounters with that neighbouring troop are more likely. We tested our two predictions using observational data from a long-term field study of two neighbouring chacma baboon troops.

\section{Materials and Methods}

\section{Study system}

We used data collected episodically over a nine-year period (2005-2013) from two neighbouring troops of chacma baboons Papio ursinus (named L and J) living at Tsaobis Nature Park $\left(22.38^{\circ} \mathrm{S}\right.$, 

riverbed. The baboons forage on sparse vegetation across this landscape as well as in patches of riparian woodland (Cowlishaw, 1997). Individuals in both troops are habituated to human observers and individually identifiable. Troop sizes (including juveniles) during this period ranged from 29-55 in troop L and 37-59 in troop J, including between 1-10 (median: 3) and 1-11 (median: 4) adult males, respectively.

Each year, a field season of variable length (2-7 months) took place, centered on the dry austral winter (details on study periods in Appendix S2). The two troops were followed daily on foot from dawn to dusk, and data on demography, behaviour, and ranging patterns were recorded. We restricted our analyses to those periods where demographic data were simultaneously available for both troops, leading to the exclusion of two field seasons (2007, 2011: Table S3). In addition, due to the routine capture of the baboon troops and three large-scale feeding experiments between 20052013, there were several periods of provisioning at fixed locations during the study (e.g. King et al., 2008). Due to the potential disruption of natural ranging patterns at these times, data from these periods were discarded (Table S3). All observation protocols were approved by the ZSL Ethics Committee and by the Ministry of Environment and Tourism in Namibia, and adhered to the ASAB/ABS Guidelines for the Treatment of Animals in Behavioural Research and Teaching.

\section{Data collection protocols}

\section{Ranging data}

The daily travel route of each troop was recorded by observers with handheld GPS. GPS fixes were taken every 30 mins from the moment the troop left the morning sleeping cliff until it reached the evening sleeping cliff. Additional GPS fixes were recorded ad libitum at each waterhole visited, when an encounter with another troop occurred, and when the troop produced alarm calls from a perceived source of danger. 


\section{Group demography}

Troop censuses were carried out at the beginning and end of each field season, and migration, birth and death events were recorded throughout. In addition, the reproductive states of females were recorded daily. In our population, oestrous cycles last $24.1 \pm 6.8$ days (range 10-45 days) and are not synchronised (Clarke et al., 2012). We categorized females as sexually receptive or not by the presence/absence of a sexual swelling (lasting on average $49.8 \pm 13.4 \%$ of the female's full oestrous cycle, median 50\%). The Operational Sex Ratio (OSR) of each troop was then calculated daily as the number of sexually receptive females divided by the number of adult males.

For each adult male, we determined whether he was born in one of the two study troops or in another troop. In 2005-2006, this was inferred by genetic relatedness and the capture history of the local baboon troops since 2000 (Huchard et al., 2010). Since 2006, males dispersing between the two troops were identified from direct observations, meaning all new unidentified males were born in an unstudied troop. From these records, we categorized males in each troop as either born in the neighbouring troop (i.e. if a male observed in troop J was born in troop L, and vice versa) or elsewhere (i.e. either born in an unstudied troop, or natal to the focal troop). For the purpose of testing our hypothesis we did not differentiate between natal males and males born in unstudied troops, since neither would be considered as knowledgeable of the neighbouring troop's range as males born in the neighbouring troop (see Appendix S1).

\section{Male dominance hierarchy}

Agonistic interactions, comprising displacements, supplants, threats, chases, and attacks, were recorded daily using ad libitum and focal observations with a standard protocol (described in Huchard \& Cowlishaw, 2011). Dominance hierarchies have been calculated each year as part of previous studies, using the I\&SI method (De Vries, 1998) implemented in Matman 1.1.4. software (Noldus Information Technology 2003) and were found to be consistently linear across all troop members (e.g., King et al. 2008, Marshall et al. 2013). During all but one field season, a single alpha 
male could be reliably identified in each troop, but the ranks of subordinate males were not always clearly resolved. In total, 10 different alpha males (out of a total of 41 adult males) were identified across both troops over the study period. There was unusually high instability in the male dominance hierarchy in 2013 in L troop (Baniel et al., 2018) but all males contesting for the alpha position at that time were born in J troop, and thus could be considered together as born in the neighbouring troop for our purposes.

We also explored the use of a dominance-weighted mean of the number of males within each troop that were born in the neighbouring troop (or not), rather than focusing only on the alphamale's origin (Appendix S3). This tested the possibility that other high-ranking males collectively influenced group movements according to their potential pre-dispersal memory. However, this variable was negatively correlated with alpha male origin (Appendix S3), introducing issues of multicollinearity (Graham, 2003). Because of this complication, and two further drawbacks of the dominance-weighted mean (the subordinate male hierarchies were not always clearly resolved, and the choice of weighting system was arbitrary), in this paper we report only those results obtained using the alpha male origin. Nevertheless, using the weighted mean did not affect our conclusions (Appendix S4).

\section{Environmental Data}

In our study area, baboons mainly forage on the leaves, flowers, berries and/or pods of either small, homogeneously scattered, herbs and dwarf shrubs in the desert hills, or larger, more localized, trees and shrubs along the dry Swakop riverbed. In the late winter months, five plant species alone makeup $92-97 \%$ of male and female feeding time, respectively (Cowlishaw, 1997). The availability of these different plant foods varies across seasons and between years: drier climatic conditions during the winter months and in drought years are characterized by a much lower availability of food, especially in the hills. At these times, the baboons focus on finding scarcer and more heterogeneously distributed food patches, mainly along the riverbed. To estimate these seasonal and inter-annual 
variations in foraging conditions, we used the Normalized Difference Vegetation Index (NDVI;

221 Pettorelli, 2013). NDVI is a satellite-based proxy of primary productivity ('greenness'). This index varies between -1 and +1 , with higher positive values representing more productive areas. We used NDVI data at a 16-day and 250m×250m resolution (MODIS 13Q1), downloaded from the NASA Land Processes Distributed Active Archive Center (Reverb|ECHO service, http://reverb.echo.nasa.gov/, 2013), across a rectangle defined by the extreme latitude and longitude reached by either troop between 2005 and 2013 plus an external margin of $0.01^{\circ}$. For the NDVI measures reported in the main text, we averaged for each 16-day period the values across all pixels of the study area. This resolution provides a coarse but informative proxy for conditions of access to food resources by baboons in our study area and period, capturing especially the within- and between-year seasonal trends (see Results). In the Tsaobis population, similar NDVI measures have been found to predict the rate of infant development during the winter period when we study them (Dezeure et al., 2020) as well as individual body condition across all age-sex classes (Cowlishaw et al., unpublished).

\section{Data processing and statistical analyses}

\section{Traditional core areas ("MASK") as proxies of male pre-dispersal memory}

To test our hypothesis, we first needed to estimate what information immigrant males could have previously acquired about their pre-dispersal ranging area. Given our annual data gaps on ranging and on the exact timing of dispersal, uncertainty about what every male could remember about predispersal ranges, and further variation arising from their different dispersal dates, it was not possible to develop individual-level memory estimates. Nevertheless, since both troops were consistently found within the same areas over our winter study periods (see below), with $L$ troop tending to range north-eastward of J troop, it was possible to use these areas to develop a troop-level estimate of

242 spatial memory that captured the different experiences of males born in different troops. These

243 "traditional" core ranging areas were thus used to define a Minimum Area of Shared Knowledge 244 ("MASK") for each troop. According to our immigrant knowledge hypothesis, if information about natal areas possessed by immigrant males from a neighbouring troop influences the ranging 
behaviour of their new resident (focal) troop, then it should affect the extent of overlap of the focal troop with that neighbour's MASK, irrespective of minor variations in memory that may occur across different males born in that neighbouring troop.

To define the MASK of each troop, we first estimated their (winter) home range for each field season. Then, for each troop, we intersected these annual range estimates to identify the MASK as the area consistently used by the troop every season we studied them (so that any male born in this troop would have experience of this area). We explored three alternative methods to estimate annual ranges (Appendix S3): Minimum Convex Polygons (MCPs) accounting for either $100 \%$ or $95 \%$ of recorded locations, and isopleth (95\% contours) of Utilisation Distributions (UDs) based on spatial kernels (using default parameterisation, see Appendix S5 for the statistical packages used). Although the MASKs show some variation in shape and size between these different methods, our conclusions remained the same irrespective of the approach adopted (Appendix S4). Unless stated otherwise we report our 95\% kernel UD results here, although occasionally we also compare these results with those obtained using the $100 \%$ MCP approach. Note that irrespective of the method used, the MASKs should not be interpreted as accurate home range estimators but rather as semi-quantitative estimates of potential differences in the spatial memory of males from different natal troops during the winter months.

The data used in the caclulation of the MASKS included all years in the sample except 2008. Because the 2008 field season was short ( $<2$ months, cf. 4.5-6.0 months in other years), the annual ranges appeared smaller than in other years $(60 \%$ and $65 \%$ of the mean other annual areas for troops J and L, respectively), and they were almost entirely contained within the intersecting area of all other annual ranges, we discarded this year from the MASK calculations (but not from the remainder of the analyses). For the remaining six years, for each troop, the size of the annual winter ranges did not correlate with the number of days of observations (Pearson's correlations, J troop: 
$t=1.28, d f=4, p=0.27 ; L$ troop: $t=1.14, d f=4, p=0.32$ ), suggesting that our annual estimates were good

271 indicators of stationary winter troop ranges.

\section{2}

273

\section{Temporal scale of analyses}

Once the two MASKs had been calculated to estimate males' memories of the ranging area traditionally used by their natal troop, we then analysed on a much finer temporal scale the extent to which a troop ranged in areas overlapping with the MASK of the neighbouring troop. For these analyses we chose to work on a temporal scale of 5-day periods, as a compromise between statistical power (finer temporal scales provide more data points) on the one hand and potential issues of both auto-correlation (at finer temporal scales, consecutive ranging and demographic records cannot be considered independent data points) and robustness to errors in GPS and/or demographic records (finer temporal scales are more sensitive to occasional mistakes by observers that can be smoothed out by averaging records over longer periods) on the other. Inspection of model residuals plotted against dates indicated there was no spatial autocorrelation. Furthermore, our conclusions were unchanged when running the same analyses with either 2- or 16-day periods (Appendix S4).

\section{Statistical models}

To test our hypothesis, we assessed how the extent of overlap of a troop's 5-day range with its neighbour's MASK (our response variable) varied in relation to the knowledge of the alpha male, the quality of the environment, and the relative number of fertile females in the focal troop (our explanatory variables). To calculate our response variable, "Overlap", we calculated the $95 \%$ kernel UD contour of each troop over each successive 5-day period, and then measured the overlap of this 5-day range with the neighbouring troop's MASK (in $\mathrm{km}^{2}$ ). Periods where more than two days out of five had $\geq 3$ hours missing GPS data were discarded. Our three explanatory variables were then calculated as 5-day means from the available daily values: alpha male knowledge, "Alpha Origin", was a binomial predictor which was scored as 1 if the alpha male was an immigrant from the neighbouring troop and 0 if he was not; environmental quality "NDVI" was a continuous predictor 
where daily values were drawn from 16-day resolution data; and the relative number of fertile females "OSRfocal" was also a continuous predictor which scored more highly when there were relatively more sexually receptive females than adult males in the focal troop. In addition, because the value of Overlap is limited by the size of the total ranging area covered by the troop during these five days, which is likely to vary, we included an additional control variable, "Area". This was calculated as the total 5-day range size, with the expectation that periods of smaller overall ranging would show lower Overlap values. Using Area as an explanatory variable (rather than as an offset) allowed us to more easily compare models with and without it (Appendix S4).

To check the robustness of our results, we also explored how our conclusions would be affected if we used alternative response variables or included additional, potentially confounding, explanatory variables. As these analyses did not change our conclusions, we only report them in Appendix S3 and Appendix S4 (which describe the definitions of these variables and overall multicollinearity structure, and the alternative model outcomes, respectively). First, with respect to alternative response variables, we explored the effects of using different methods to calculate the MASK and 5-day range, on which the Overlap variable is based, comparing between MCPs and 95\% kernel UDs. We also re-ran our models replacing Overlap with a response variable quantifying the time spent in the neighbouring MASK rather than the extent of spatial overlap, assessed as the proportion of all GPS locations of each 5-day period falling into the neighbouring MASK. Second, with respect to additional explanatory variables, we explored the influence of the relative number of fertile females over adult males in the neighbouring (rather than focal) troop ("OSRneighbour"), the dominance-weighted mean of all males' origins in the focal troop ("MalesOri"), and the difference in NDVI values between the two neighbouring MASKs ("DiffNDVI") on patterns of Overlap.

In total, 171 5-day periods from seven seasons between 2005 and 2013 were analyzed (for further details on data structure, see Appendix S2). We used linear mixed models (LMMs) with the response and explanatory variables described above, further including interactions between Alpha 
origin and both NDVI and OSRfocal to test Predictions 1 and 2 respectively, i.e., that a troop containing a knowledgeable alpha male will show greater range overlap with their neighbour's MASK when food is scarce, but lower overlap when his troop contains relatively more fertile females, respectively. Our random effects comprised year, troop and alpha male identity, to control for the potential non-independence of data from particular males in a troop within and across years. We checked and corrected for co-linearity between our explanatory variables (Appendix S3), following the residual (or sequential) regression approach (following Graham 2003). We therefore replaced NDVI with the residuals of NDVI (resNDVI) regressed against Area to avoid co-linearity effects between these variables (see Appendix S3). However, including NDVI (instead of resNDVI) without Area in the models led to the same conclusions (Appendix S4).

We computed (with maximum-likelihood estimation) all nested models from the full model and ranked them by Akaike's Information Criterion corrected for small sample size (AICC). We then discarded "uninformative" models that were nested within better ranked models, without decreasing AICc values of more than 2 units per parameter added (Arnold, 2010). We present a model-averaging outcome of this ranking and the support for retaining each variable. We checked the first-ranking model's validity (variance homogeneity and balanced residual values) by visual inspection of residuals versus fitted values and versus date.

All analyses were carried in the R environment version 3.1.3 (2015-03-09). Packages used for analyses and their associated references are listed in Appendix S5. Data and code will be deposited in Dryad following acceptance for publication. 
Large-scale home ranges: stability and variability through time

The baboon troop "winter" ranges at Tsaobis (Fig.1A), estimated by the $95 \%$ kernel Utilization

Distribution (UD) during each field season, extended from $13.3 \mathrm{~km}^{2}$ to $33.0 \mathrm{~km}^{2}$ in J troop (mean = $24.0 \mathrm{~km}^{2}$, median $\left.=26.8 \mathrm{~km}^{2}\right)$, and from $24.6 \mathrm{~km}^{2}$ to $44.9 \mathrm{~km}^{2}$ in $\mathrm{L}$ troop $\left(\right.$ mean $=33.7 \mathrm{~km}^{2}$, median $=$ both the absolute size of the MASKs and their location relative to one another, regardless of the method used to calculate them (see Fig.1C and Appendix 3), shows that a significant part of each troop's range, i.e., the MASK, remained stable across field seasons.

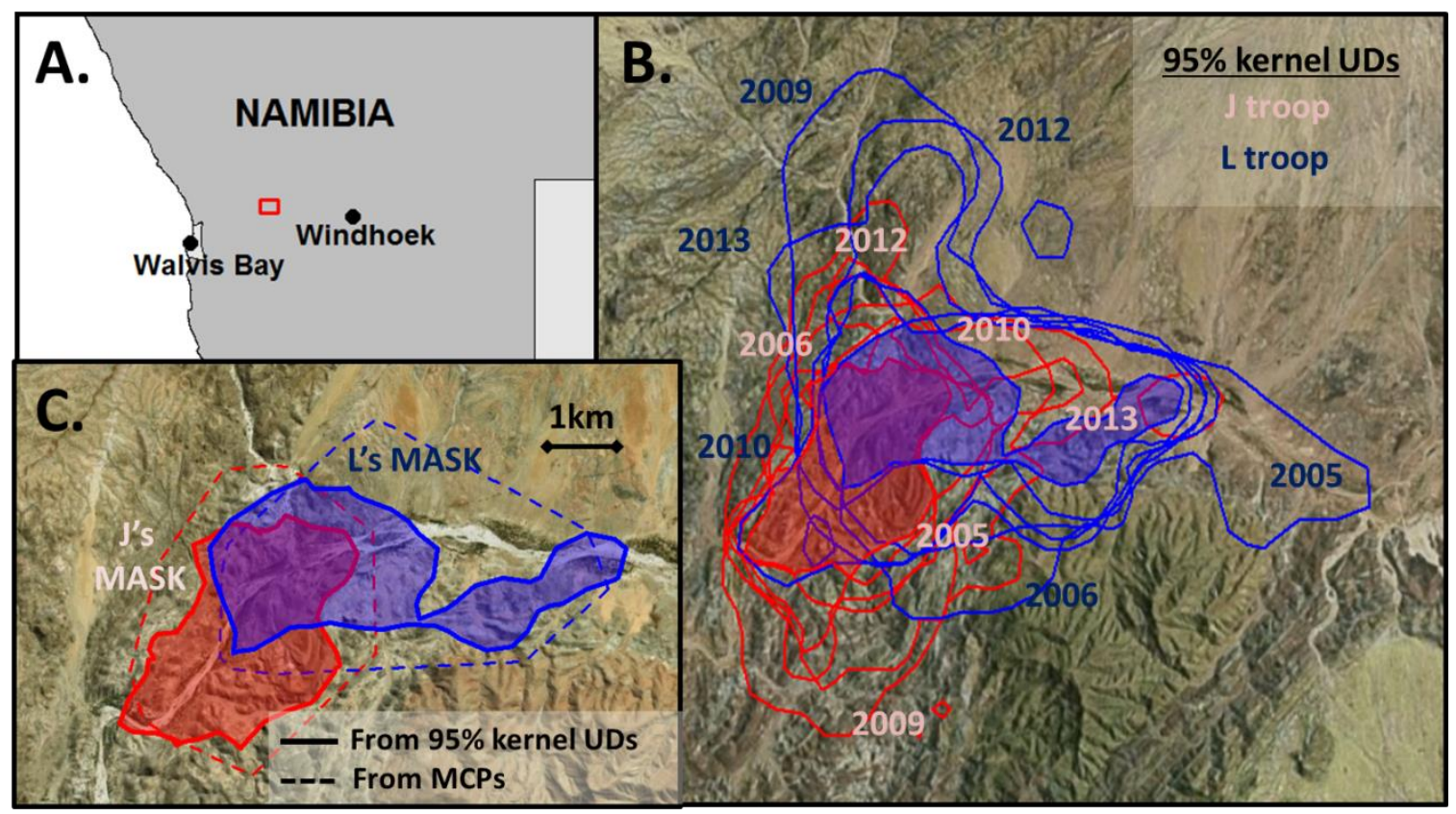




\section{General overlap with the neighbour's MASK every 5 days}

Troops showed extensive variation in their overlap with the neighbouring troop's MASK (Fig.2A) and more generally in the total area they covered during each 5-day period (Area: J troop, mean and s.d. covered larger areas (mean model weight for Area $=1.00$; Table 1). When troops overlapped with the

371 neighbouring MASK (Overlap value $>0$ ), most of the overlap surface was within the shared part

372 common to both MASKs (mean \pm s.d.: $71.3 \pm 22.5 \%$, median: $65.9 \%$, the shared area between MASKs

373 represented at least $40 \%$ of the Overlap in $95 \%$ of 5 -day Overlap values, these proportions were even greater when considering MCP-based MASKs) and therefore largely remained within the focal troop's

375 MASK rather than venturing into the "exclusive part" of the neighbour's MASK. 
A.

B.
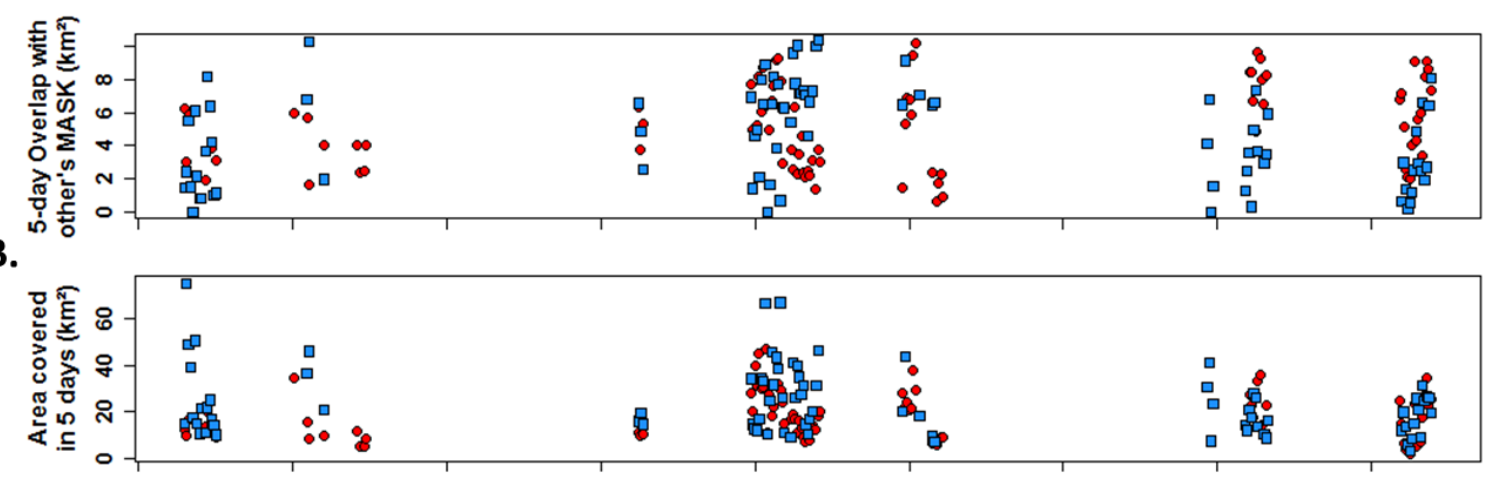

C.

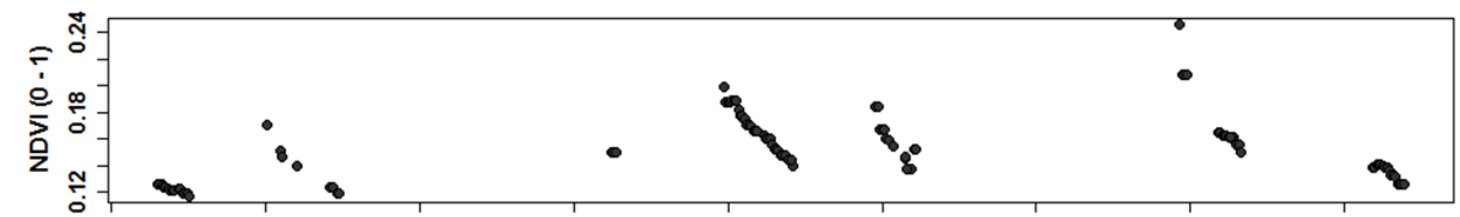

D.

E.
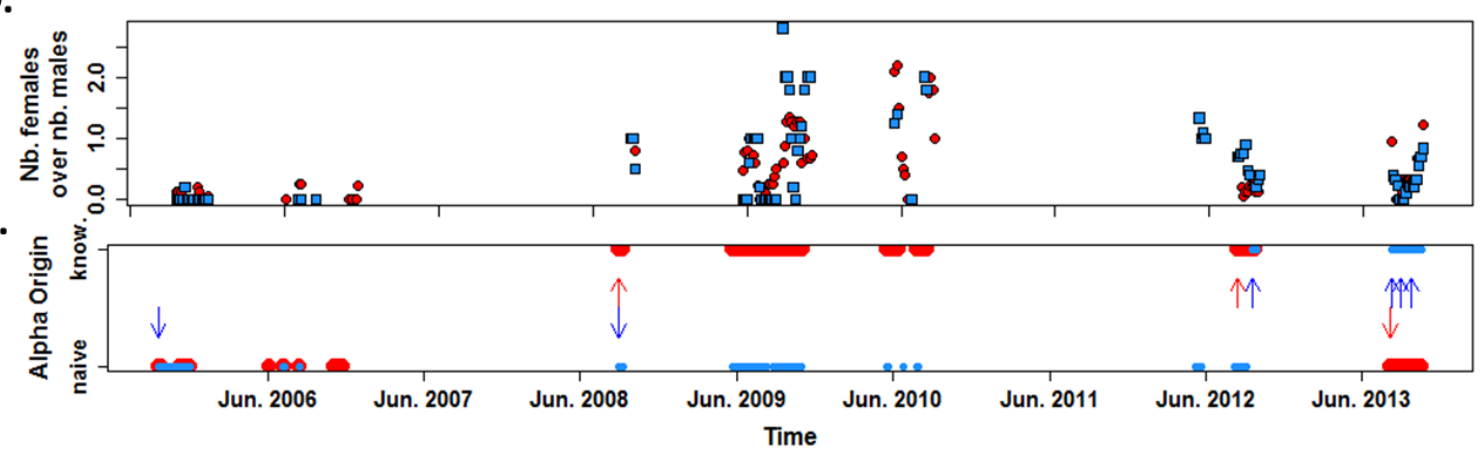

Figure 2: Time series used for our analyses (red: J troop; blue: L troop; black: common to both troops) in top-to-bottom order (panels A-E, respectively): Overlap; Area; NDVI (before correction for collinearity with Area); OSRfocal; and Alpha Origin ("know.": alpha male born in the neighbouring troop; "naïve": alpha male NOT born in the neighbouring troop; arrows indicate change of alpha male identity).

Testing the Immigrant Knowledge hypothesis

Our test of the immigrant Knowledge hypothesis utilised marked variation in NDVI, the focal troop's operational sex ratio, and the origin of the focal troop's alpha male, across the study period (Fig.2C-E, respectively). Assessment of the interaction terms in the full, averaged, model (Table 1) found little support for Prediction 1 (Alpha Origin*resNDVI), according to both the low AlCc weight and sensitivity of both the AICc weight and sign of the estimator sensitive to alternative modelling decisions (see Appendix S4). Thus, there was no clear tendency for troops containing a knowledgeable alpha male to show greater home range range overlap with that male's natal troop range when primary productivity declined. However, there was strong support for Prediction 2 
(Alpha Origin*OSRfocal), with respect to both a high AICc weight and the consistent sign of the estimator regardless of alternative modelling decisions (Appendix S4). Thus, when troops contained a knowledgeable alpha male they showed lower range overlap with that male's natal troop range than when they contained relatively more fertile females (Fig.3). Unexpectedly, this interaction also indicated the reverse pattern was observed when the alpha male was not knowledgeable, i.e., that troops showed greater range overlap with their neighbour when they contained relatively more fertile females (Fig.3).

\begin{tabular}{|c|c|c|c|c|}
\hline & Estimate & $\begin{array}{c}\text { Adjusted } \\
\text { Std. Error }\end{array}$ & $\mathbf{z}$ & $\begin{array}{c}\text { AlCc } \\
\text { weight }\end{array}$ \\
\hline (Intercept) & 2.11 & 0.94 & 2.248 & \\
\hline Alpha origin (born in neighbouring troop) & 1.22 & 0.78 & 1.565 & 1 \\
\hline Area & 0.10 & 0.01 & 7.739 & 1 \\
\hline OSRfocal & 1.56 & 0.39 & 4.061 & 1 \\
\hline $\begin{array}{c}\text { Alpha origin (born in neighbouring troop) } \\
\text { * OSRfocal }\end{array}$ & -2.95 & 0.64 & 4.604 & 1 \\
\hline NDVI (res) & $\begin{array}{c}-5.46 \mathrm{e}- \\
4\end{array}$ & $1.08 \mathrm{e}-03$ & 0.502 & 0.28 \\
\hline $\begin{array}{c}\text { Alpha origin (born in neighbouring troop) } \\
\text { * NDVI (res) }\end{array}$ & $8.82 \mathrm{e}-04$ & $1.91 \mathrm{e}-03$ & 0.460 & 0.28 \\
\hline
\end{tabular}

398

Table 1: Average model of Overlap (extent of focal troop's overlap with neighbouring troop's MASK), based on AICc 


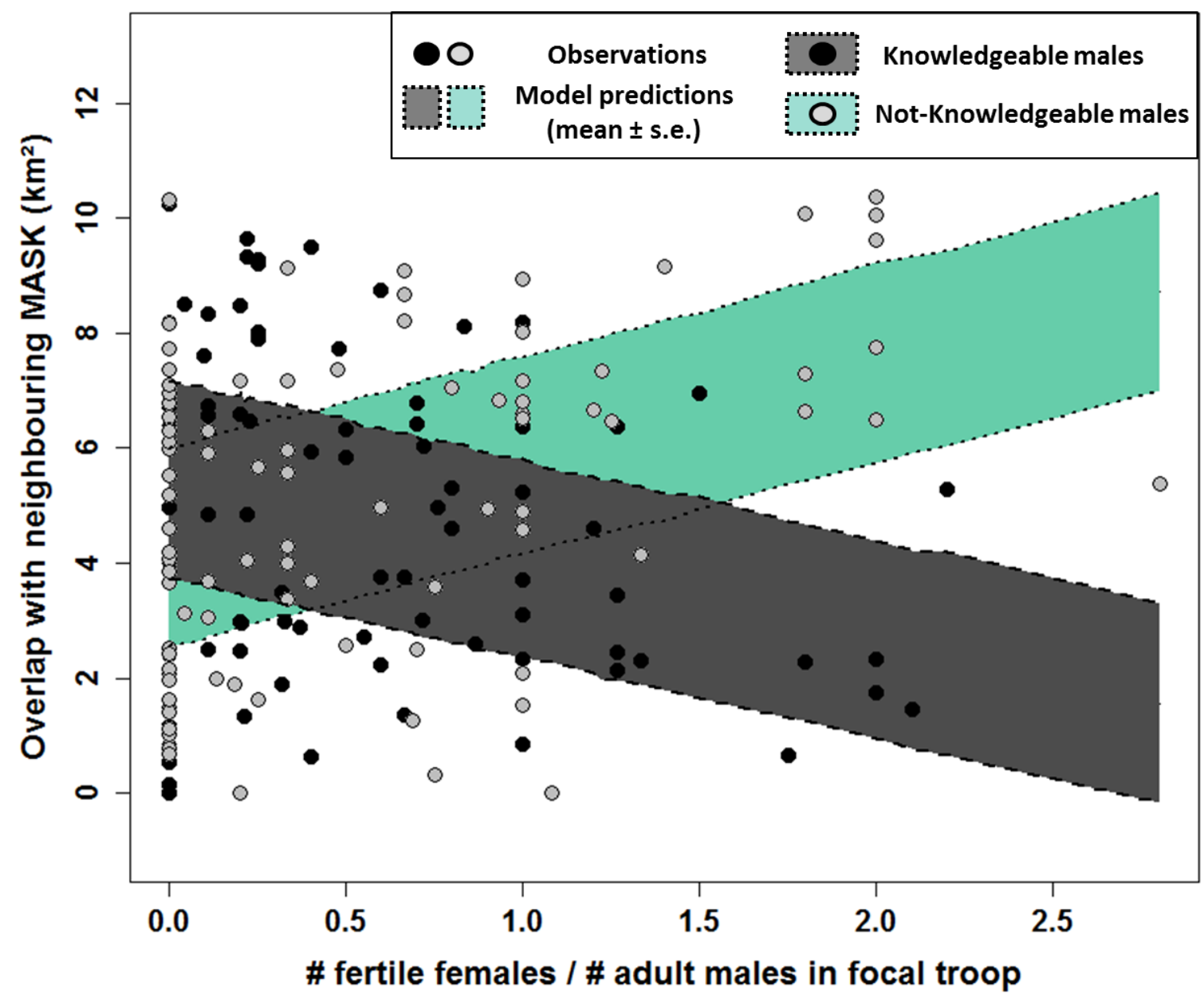

406

Figure 3: Observed (dots) and modelled (shaded) values of Overlap of a troop over the neighbouring MASK, per 5-day grey shading) or not ("not knowledgeable": light grey circles, green shading) as a function of the relative number of model uncertainty. 
We found that alpha males' natal origins helped to predict range overlap dynamics between neighbouring baboon groups, consistent with the immigrant knowledge hypothesis. Specifically, in support of our Prediction 2, when a focal troop contained a greater number of fertile females relative to males it was more likely to avoid overlap with a neighbouring troop (consistent with males' adaptive interests; Appendix S1), but only when its alpha male was an immigrant from that troop and not when the alpha male had another origin. However, contrary to Prediction 1, we found no evidence for an effect of alpha male knowledge on range overlap that was dependent upon our NDVI measure of foraging conditions. Overall, these results suggest that, in baboons, when alpha males exert an influence on troop movements, this influence is more likely to be in response to mating competition than to foraging conditions. Furthermore, our results suggest that the dispersal of male baboons may act to increase rather than decrease spatial segregation between the pre- and postdispersal troops.

Our approach is indirect in its estimation of group members' respective knowledge and their influence on collective movement decisions, and relies on our review of the potential costs and benefits of overlapping with the neighbouring MASK for different troop members (Appendix S1). The observation that the focal troop increased overlap with the neighbour's home range when the alpha male was not originating from this neighbouring troop and it was against his adaptive interests (i.e., when there was an excess of fertile females relative to males in his troop) suggests that these alpha males were not influencing collective movements at these times. The fact that this increase in overlap would be beneficial to the fertile females in the focal troop but detrimental to all other adult troop members (Appendix S1) suggests that it was these females who drove these movements. Yet the reverse patterns of overlap were observed when alpha males were immigrants from that neighbouring troop. This interaction effect of alpha male origin and mating competition is difficult to explain without assuming a difference in the knowledge (or use of knowledge) of alpha males of different origins exerting an influence on collective movements. 
441 between males of different pre-dispersal origins - seems the most parsimonious explanation. Indeed, 442 even though our two troops showed extensive range overlap over our study period, each had distinct home ranges consistently used over the years. If we split each troop's MASK into two sections, according to whether or not it overlaps with it's neighbour's MASK, and call the exclusive, nonoverlapping section the 'core area', it is clear that visits to the core area of one troop by the other troop were rare and limited (i.e. overlap between neighbouring MASKs was mainly restricted to the same small area over the years, common to both MASKs, Fig.1). This supports the view that individuals should not possess or make use of similar spatial memories if they belong to different troops, since there is no other identified mechanism of spatial segregation in the absence of territoriality (Börger et al., 2008; Riotte-Lambert et al., 2015). Nevertheless, it does seem likely that males would eventually learn to identify the whereabouts of the neighbouring troops, e.g., by monitoring where they encounter them (Ellison et al., 2020; Markham et al., 2013), leading to the fading away of the male origins effect as time since immigration passes. Unfortunately, our sample size and uncertainty on some immigration dates did not permit a direct test of this prediction. Male baboons in captivity can demonstrate remarkable learning capacities (Fagot \& Cook, 2006), yet in contrast to these controlled experimental situations, there are several sources of noise that may affect learning rates in the wild, including the fact that neighbours will not always be present in the area of overlap between neighbouring home ranges. Despite extensive exploration of potential mechanisms involved.

Apart from pre-dispersal memory, males of different origins also differ in their kin relationships with neighbouring troops. Consequently, the differential avoidance patterns we report 
explain why the avoidance effect is not observed permanently rather than when there is a relative excess of fertile females in the focal troop (Table 1, Fig.3). We explore and discuss some additional explanations trying to reconcile inbreeding avoidance and kin competition with our results in the supplementary information (see Appendices S1, S3 and S4). In a nutshell, these additional analyses (Appendix S3) suggest that there may be effects of inbreeding and/or kin competition, but if so they are additive rather than competing with the effects of mating competition reported in the main paper (Appendix S4). However, these analyses also received less statistical support and were less robust to alternative modelling decisions (Appendix S4). This is unsurprising, given the relatively lower costs of inbreeding in comparison to the costs associated with male-male competition for dominance and access to mates, and the risks of infanticide by neighbouring males (as captured by our OSRfocal index, Appendix S1).

Notwithstanding these discussions on the exact behavioural mechanisms involved, our results suggest that mating competition may have a strong influence on home range overlap dynamics, consistent with a previous study in another baboon species (Markham et al., 2013). This finding is in line with the fact that male dispersal decisions are generally related to reproductive opportunities and constraints, such as the operational sex ratios of the natal and target troops and inbreeding avoidance (Alberts \& Altmann, 1995; Packer, 1979). Substantial work has described how range size and overlap vary with sex and reproductive season in solitary species (e.g. Attuquayefio et al., 1986; Edelman \& Koprowski, 2006), while in social species research has tended to focus on the wider relationships found between home range and mating systems (Clutton-Brock, 1989; Emlen \& Oring, 1977). Yet (Markham et al., 2013) noted that mating strategies are rarely considered in finerscale studies looking at how neighbouring social groups dynamically use and share space, and we have been unable to find any further research in this area since Markham et al.'s study. The mechanistic framework we have developed here suggests a possible general explanation for this deficiency. Analyses that do not account for temporal fluctuations in both the divergent adaptive interests between group members (e.g. arising from fluctuations in members' reproductive status) 
and fluctuations in members' influences on collective movements (e.g. arising from changes in group composition and dominance hierarchies) may result in the averaging-out of the fluctuating effects of mating competition on group ranges, making the detection of such effects extremely difficult (e.g. see sensitivity analyses in Markham et al., 2013). For instance, we would not have detected our observed effect of mating competition on overlap had we not accounted for a mechanistic interaction term with alpha males' origin (Fig.3). The development of more mechanistic approaches to collective home range behaviour (Börger et al., 2008; Conradt et al., 2009; Couzin et al., 2005) may thus help to better reveal such cryptic forces at play on group ranging dynamics.

In contrast with previous studies, where a disproportionate influence of the alpha male on baboon troop movements was revealed by experimentally manipulating food distribution (Kaplan et al., 2011; King et al., 2008), we did not find support for Prediction 1: i.e., natural variation in foraging conditions did not reveal an influence of alpha males on group ranging behaviour. One explanation is that our NDVI index poorly reflects fine temporal scale variation in local food availability, especially since baboons can be opportunistic, generalist foragers. Yet our index strongly correlated with the 5day range sizes (Area) of troops, capturing well this aspect of variation in baboon foraging behaviour. In our study population, as NDVI declines with the die-back of vegetation during the dry winter season (Fig.2), food resources for the baboons become more concentrated in spatially restricted riparian areas, leading to a reduction in the baboons' 5 -day ranges and indirectly to a reduction in overlap with the neighbouring troop. We also observed that overlap was rare with the exclusive part of the neighbouring troop's MASK (see above), suggesting that even if our measure of food availability is imperfect, males rarely use their memory to range into these 'core areas' of their predispersal troop. An alternative explanation for the lack of support for Prediction 1 may be that males have little adaptive interest in influencing collective movements for foraging. Specifically, because food is patchy and monopolisable, alpha males have priority of access and are therefore rarely motivated to incur the costs of leadership to guide their troop to alternative foraging grounds, in contrast to previous studies where the distribution of food was artificially manipulated to exceptional 
levels (Kaplan et al., 2011; King et al., 2008). The observed lack of alpha male response to low food

519 availability may also reflect a minimal difference in range quality between the two troops (Appendix

520 S3). Overall, our support for Prediction 2 (male influence dependent on mating competition) and not

521 for Prediction 1 (male influence dependent on food availability) is consistent with a general trend across mammals for male reproductive success to be more strongly limited by mating competition than access to food (e.g. Clutton-Brock, 2016).

Our study has clear limits: it was conducted on only two troops for a relatively limited number of years, our model of males' memory is rudimentary, and further work is needed to validate our mechanistic interpretations. Yet our results are very robust to alternative modelling decisions (Appendix S4), and seem to fit very well with what we know about the socio-ecology of baboons (Appendix S1) and other social mammals (Clutton-Brock, 2016). We hope that our study will help to promote promising new approaches and research questions to understanding the processes underlying home range dynamics in social species. Our results may help to resolve the apparent contradictions in the literature on collective movement mechanisms in baboon groups (King et al., 2008; Strandburg-Peshkin et al., 2015), by suggesting that the influence each individual exerts may be highly context-dependent within troops. More generally, our results suggest that dispersal and memory could act to increase spatial segregation between pre- and post-dispersal groups, rather than act as a form of cultural transmission of space use between groups. Finally, our results also emphasize that mating strategies may play a key but overlooked role in how groups dynamically

537 share space. Altogether, we suggest that accounting for the underlying processes of collective decision-making and/or individual knowledge may help to better reveal the determinants of ranging behaviour in social species. Home range behaviour and space use mediate a variety of ecological encounters, with resources, pathogens, and conspecifics. To better understand and predict such encounters in a rapidly changing world, we thus hope our study will inspire further research on the social- and information-related processes underlying home range dynamics across species. 
543

544

545

546

547

548

549

550

551

552

553

554

555

556

557

558

559

560

561

562

563

564

\section{Authors' contributions}

GC directed the long-term field study; JC, NP \& GC conceived the ideas and designed methodology; $A B, A C, A K, A L, H M, E H \& G C$ managed and carried data collection and storage and provided dominance hierarchies established in previous studies ; JC analyzed the data ; JC \& GC led the writing of the manuscript, all authors enthusiastically and critically contributed to the drafts and approved submission.

\section{Acknowledgments}

We are grateful to all the Tsaobis Baboon Project volunteers between 2005-13 for their invaluable help in the field. Permission to work at Tsaobis Nature Park was granted by the Swart family (2005-6) and the Ministry of Lands and Resettlement and the Tsaobis beneficiaries (2007-13). Thanks also to the Gobabeb Research and Training Centre for affiliation, and the Ministry of Environment and Tourism for research permits, as well as to the Snyman and Wittreich families for permission to work on their land. We thank the editors and two anonymous reviewers for their constructive feedback on our manuscript.

\section{Funding}

This work was supported by a Fenner School of Environment and Society Scholarship awarded to AJC, three Ministère de l'Education et de la Recherche Studentships awarded to $A B, E H$, and JC, an Ecole Normale Superieure de Lyon's studentships awarded to JC, a post-doctoral fellowship funded by the Templeton World Charity Foundation's 'Diverse Intelligences' scheme (grant TWCF0316 to Dora Biro) awarded to JC, three Natural Environment Research Council (NERC) Studentships awarded to AJK, AEGL, and HMM, and a NERC Advanced Research Fellowship awarded to GC. This paper is a publication of the ZSL Institute of Zoology's Tsaobis Baboon Project, supported by Research England. 


\section{Data availability statement}

Analyses reported in this article can be reproduced using the data provided by Collet et al (2021): doi:10.5061/dryad.j3tx95xfw

\section{References}

Alberts, S. C., \& Altmann, J. (1995). Balancing Costs and Opportunities: Dispersal in Male Baboons. The American Naturalist, 145(2), 279-306. https://doi.org/10.2307/2463127

Attuquayefio, D., Gorman, M., \& Wolton, R. (1986). Home range sizes in the wood mouse Apodemus sylvaticus: Habitat, sex and seasonal differences. Journal of Zoology, 210(1), 45-53.

Baniel, A., Cowlishaw, G., \& Huchard, E. (2018). Context dependence of female reproductive competition in wild chacma baboons. Animal Behaviour, 139, 37-49.

Börger, L., Dalziel, B. D., \& Fryxell, J. M. (2008). Are there general mechanisms of animal home range behaviour? A review and prospects for future research. Ecology Letters, 11(6), 637-650. https://doi.org/10.1111/j.1461-0248.2008.01182.x

Brent, L. J. N., Franks, D. W., Foster, E. A., Balcomb, K. C., Cant, M. A., \& Croft, D. P. (2015). Ecological Knowledge, Leadership, and the Evolution of Menopause in Killer Whales. Current Biology, 25(6), 746-750. https://doi.org/10.1016/j.cub.2015.01.037

Burt, W. H. (1943). Territoriality and Home Range Concepts as Applied to Mammals. Journal of Mammalogy, 24(3), 346-352. https://doi.org/10.2307/1374834

Cavalli-Sforza, L. L., \& Feldman, M. W. (1981). Cultural transmission and evolution: A quantitative approach. Princeton University Press.

Clarke, P., Henzi, S., \& Barrett, L. (2012). Estrous synchrony in a nonseasonal breeder: Adaptive strategy or population process? Behavioral Ecology, 23(3), 573-581.

Clutton-Brock, T. (1989). Review lecture: Mammalian mating systems. Proceedings of the Royal Society of London B: Biological Sciences, 236(1285), 339-372.

Clutton-Brock, T. (2016). Mammal societies. John Wiley \& Sons. 
Collet, J., Pettorelli, N., Baniel, A., Carter, A., Huchard, E., King, A. J., Lee, A. E. G., Marshall, H. H., \& Cowlishaw, G. (2021). Data from: Immigrant males' knowledge influences baboon troop movements to reduce home range overlap and mating competition. Behavioral Ecology. doi:10.5061/dryad.j3tx95xfw

Conradt, L., Krause, J., Couzin, I. D., \& Roper, T. J. (2009). "Leading According to Need” in SelfOrganizing Groups. The American Naturalist, 173(3), 304-312. https://doi.org/10.1086/596532

Cote, J., \& Clobert, J. (2007). Social information and emigration: Lessons from immigrants. Ecology Letters, 10(5), 411-417.

Couzin, I. D., Krause, J., Franks, N. R., \& Levin, S. A. (2005). Effective leadership and decision-making in animal groups on the move. Nature, 433(7025), 513-516. https://doi.org/10.1038/nature03236

Cowlishaw, G. (1997). Trade-offs between foraging and predation risk determine habitat use in a desert baboon population. Animal Behaviour, 53(4), 667-686. https://doi.org/10.1006/anbe.1996.0298

De Vries, H. A. N. (1998). Finding a dominance order most consistent with a linear hierarchy: A new procedure and review. Animal Behaviour, 55(4), 827-843.

Dezeure, J., Dagorrette, J., Baniel, A., Carter, A. J., Cowlishaw, G., Marshall, H., Martina, C., Raby, C. L., \& Huchard, E. (2020). Developmental transitions in body color in chacma baboon infants: Implications to estimate age and developmental pace. American Journal of Physical Anthropology, e24118.

Duncan, C., Nilsen, E. B., Linnell, J. D. C., \& Pettorelli, N. (2015). Life-history attributes and resource dynamics determine intraspecific home-range sizes in Carnivora. Remote Sensing in Ecology and Conservation, 1(1), 39-50. https://doi.org/10.1002/rse2.6

Edelman, A., \& Koprowski, J. (2006). Seasonal changes in home ranges of Abert's squirrels: Impact of mating season. Canadian Journal of Zoology, 84(3), 404-411. 
Ellison, N., Hatchwell, B. J., Biddiscombe, S. J., Napper, C. J., \& Potts, J. R. (2020). Mechanistic home range analysis reveals drivers of space use patterns for a non-territorial passerine. Journal of Animal Ecology, 89(12), 2763-2776. https://doi.org/10.1111/1365-2656.13292

Emlen, S. T., \& Oring, L. W. (1977). Ecology, sexual selection, and the evolution of mating systems. Science, 197(4300), 215-223.

Fagot, J., \& Cook, R. G. (2006). Evidence for large long-term memory capacities in baboons and pigeons and its implications for learning and the evolution of cognition. Proceedings of the National Academy of Sciences, 103(46), 17564-17567. https://doi.org/10.1073/pnas.0605184103

Foley, C., Pettorelli, N., \& Foley, L. (2008). Severe drought and calf survival in elephants. Biology Letters, 4(5), 541-544. https://doi.org/10.1098/rsbl.2008.0370

Graham, M. H. (2003). Confronting multicollinearity in ecological multiple regression. Ecology, 84(11), 2809-2815. https://doi.org/10.1890/02-3114

Henrich, J., \& Boyd, R. (1998). The evolution of conformist transmission and the emergence of between-group differences. Evolution and Human Behavior, 19(4), 215-241.

Huchard, E., \& Cowlishaw, G. (2011). Female-female aggression around mating: An extra cost of sociality in a multimale primate society. Behavioral Ecology, 22(5), 1003-1011.

Huchard, E., Knapp, L. A., Wang, J., Raymond, M., \& Cowlishaw, G. (2010). MHC, mate choice and heterozygote advantage in a wild social primate. Molecular Ecology, 19(12), 2545-2561. https://doi.org/10.1111/j.1365-294X.2010.04644.x

Jacob, S., Chaine, A. S., Schtickzelle, N., Huet, M., \& Clobert, J. (2015). Social information from immigrants: Multiple immigrant based sources of information for dispersal decisions in a ciliate. Journal of Animal Ecology.

Kaplan, B. S., O'Riain, M. J., van Eeden, R., \& King, A. J. (2011). A Low-Cost Manipulation of Food Resources Reduces Spatial Overlap Between Baboons (Papio ursinus) and Humans in Conflict. 
International Journal of Primatology, 32(6), 1397-1412. https://doi.org/10.1007/s10764-011$9541-8$

Kelt, D. A., \& Van Vuren, D. H. (2001). The ecology and macroecology of mammalian home range area. The American Naturalist, 157(6), 637-645.

King, A. J., Douglas, C. M. S., Huchard, E., Isaac, N. J. B., \& Cowlishaw, G. (2008). Dominance and Affiliation Mediate Despotism in a Social Primate. Current Biology, 18(23), 1833-1838. https://doi.org/10.1016/j.cub.2008.10.048

Kranstauber, B., Gall, G. E., Vink, T., Clutton-Brock, T., \& Manser, M. B. (2019). Long-term movements and home-range changes: Rapid territory shifts in meerkats. Journal of Animal Ecology.

Luncz, L. V., \& Boesch, C. (2014). Tradition over trend: Neighboring chimpanzee communities maintain differences in cultural behavior despite frequent immigration of adult females. American Journal of Primatology, n/a-n/a. https://doi.org/10.1002/ajp.22259

Markham, A. C., Guttal, V., Alberts, SusanC., \& Altmann, J. (2013). When good neighbors don't need fences: Temporal landscape partitioning among baboon social groups. Behavioral Ecology and Sociobiology, 67(6), 875-884. https://doi.org/10.1007/s00265-013-1510-0

Mesoudi, A. (2018). Migration, acculturation, and the maintenance of between-group cultural variation. PloS One, 13(10).

Montanari, D. (2019). Group Coordination During Collective Movements in Guinea Baboons (Papio Papio). Georg-August-Universität Göttingen.

Packer, C. (1979). Inter-troop transfer and inbreeding avoidance in Papio anubis. Animal Behaviour, 27, Part 1(0), 1-36. https://doi.org/10.1016/0003-3472(79)90126-X

Pearce, F., Carbone, C., Cowlishaw, G., \& Isaac, N. J. B. (2013). Space-use scaling and home range overlap in primates. Proceedings of the Royal Society B: Biological Sciences, 280(1751). https://doi.org/10.1098/rspb.2012.2122

Pettorelli, N. (2013). The normalized difference vegetation index. Oxford University Press. 
Riotte-Lambert, L., Benhamou, S., Bonenfant, C., \& Chamaillé-Jammes, S. (2017). Spatial memory shapes density dependence in population dynamics. Proceedings of the Royal Society B: Biological Sciences, 284(1867). https://doi.org/10.1098/rspb.2017.1411

Riotte-Lambert, L., Benhamou, S., \& Chamaillé-Jammes, S. (2015). How memory-based movement leads to nonterritorial spatial segregation. The American Naturalist, 185(4), E103-16. https://doi.org/10.1086/680009

Spencer, W. D. (2012). Home ranges and the value of spatial information. Journal of Mammalogy, 93(4), 929-947.

Strandburg-Peshkin, A., Farine, D. R., Couzin, I. D., \& Crofoot, M. C. (2015). Shared decision-making drives collective movement in wild baboons. Science, 348(6241), 1358-1361. https://doi.org/10.1126/science.aaa5099

Strandburg-Peshkin, A., Papageorgiou, D., Crofoot, M. C., \& Farine, D. R. (2018). Inferring influence and leadership in moving animal groups. Philosophical Transactions of the Royal Society B: Biological Sciences, 373(1746), 20170006.

Stueckle, S., \& Zinner, D. (2008). To follow or not to follow: Decision making and leadership during the morning departure in chacma baboons. Animal Behaviour, 75(6), 1995-2004. https://doi.org/10.1016/j.anbehav.2007.12.012

van de Waal, E., Borgeaud, C., \& Whiten, A. (2013). Potent social learning and conformity shape a wild primate's foraging decisions. Science, 340(6131), 483-485.

Wakefield, E. D., Bodey, T. W., Bearhop, S., Blackburn, J., Colhoun, K., Davies, R., Dwyer, R. G., Green, J. A., Grémillet, D., Jackson, A. L., Jessopp, M. J., Kane, A., Langston, R. H. W., Lescroël, A., Murray, S., Le Nuz, M., Patrick, S. C., Péron, C., Soanes, L. M., ... Hamer, K. C. (2013). Space Partitioning Without Territoriality in Gannets. Science, 341(6141), 68-70. https://doi.org/10.1126/science.1236077 
690 Whiten, A., Spiteri, A., Horner, V., Bonnie, K. E., Lambeth, S. P., Schapiro, S. J., \& de Waal, F. B. M.

691

692

693

694

695

696

697 (2007). Transmission of Multiple Traditions within and between Chimpanzee Groups. Current Biology, 17(12), 1038-1043. https://doi.org/10.1016/j.cub.2007.05.031

Wolf, M., Frair, J., Merrill, E., \& Turchin, P. (2009). The attraction of the known: The importance of spatial familiarity in habitat selection in wapiti Cervus elaphus. Ecography, 32(3), 401-410. https://doi.org/10.1111/j.1600-0587.2008.05626.x 